\title{
nature
}

\section{Human genome projects: work in progress}

Whatever doubts there may be about the timing, public celebrations of genome projects are well deserved. Researchers should now be left to complete significant tasks that remain, and to tidy up troublesome errors in their databases.

$\mathrm{F}$ rancis Collins and his colleagues at the head of the publicly funded Human Genome Project deserve praise, not only for their science, but for their openness, their discipline, their international perspective and for their systematic approach. That surely represents a model to be supported for future large programmes in biology. Craig Venter and his colleagues at the private company Celera deserve credit for the technical imagination and competitiveness without which the world would probably be waiting a lot longer for these results to emerge. And where, as here, competitiveness and technical complementarity go hand in hand, science benefits too.

But, given the significantly incomplete nature of the research in both projects, why the presidential and prime ministerial fanfares (see page 983), and why this week in particular?

Anyone interested in the human genome projects will have become familiar with two sorts of public announcements: those in scientific journals and those not linked to any peer-reviewed publication. This week's extravagant examples of the latter reached an alltime zenith or nadir, according to taste. One might have been forgiven for forgetting that there are months to go before even a draft sequence will be scientifically useful. But that fact need not prevent congratulations going where they are already due.

Both private and public projects have issued a series of announcements that have helped maintain a high public profile, with one eye on share prices, no doubt, in the former case, and on political representatives in the latter. None has been as scientifically arbitrary in its timing as this week's festivities, where even the scientifically useful 'draft' is still incomplete by previously suggested definitions. But there has been increasing pressure on both projects to deliver something that their private or public investors - not to mention the media - could celebrate. And, as the public are represented by politicians only too pleased to identify themselves with the achievement, in the end there was no way the projects could wait for the months required to make the draft publishable. Above all, the bickering needed to be stopped.

Even sceptical purists must hope that this week's celebration will not only boost public confidence to appropriate levels but will also take the spotlight off the two, in order that completion of a scientifically useful draft can be most effectively achieved.

But even that can be expected to leave significant gaps. Not only will that sequence be incomplete (by definition), but the published 'annotation', the identification of genes and of their function, will contain many uncertainties (see page 984). If, despite Celera's commercial interests and status, it and the public project can find a way of benefiting from each other so as to hasten completion of the sequence and to help speed up its public annotation, so much the better.

But there remains a related problem. More attention must be given to the accuracy of public databases into which sequences and annotation are being deposited. These contain errors that could themselves take years to clean up. Biologists encountering such errors should be doing more to provide the feedback to databases and to original depositing authors to achieve corrections. Better still, Bill Clinton, Tony Blair and others should press for dedicated funds for that unglamorous but essential curatorial purpose.

\section{Bad clinical practices}

\section{When it comes to research, Germany's medical profession may have a lot to answer for.}

s there just one rotten apple in the barrel? Or is the barrel itself contaminated? There are many in Germany who believe that the suspicions of scientific misconduct raised against three clinical researchers, originally from Freiburg (see Nature 405, 871-872; 2000 ), is a sign that the system of clinical research and promotion in Germany provides a breeding ground for bad scientific practice.

Suspicions against the researchers were revealed during a twoyear independent analysis of research papers stemming from the laboratory of prominent Freiburg clinician Roland Mertelsmann, in the wake of the scandal surrounding Mertelsmann's former righthand man, Friedhelm Herrmann. A couple of years ago, Herrmann's meteoric career crashed following charges that data had been fabricated in many of his research papers. The careers of two others which were also launched from the Mertelsmann group are now in question after the task force that conducted the analysis presented evidence of data manipulation in their Habilitation theses. (Habilitation is a high-level research qualification required for an academic career, particularly in the clinical sciences.)

Charges of scientific negligence have been brought against Mertelsmann himself. Whatever the outcome, there is a glaring paradox in the clinical system in Germany: although a long publication list is required for any top clinical position — even for those positions where no research will ever be done - there is no formal requirement for any training in research methods. On top of this, clinicians are not given leave from their wards for their research; data must be collected after hours. That is a blueprint for trouble.

The solution is as obvious as the paradox: Habilitation should be scrapped. Promotion should be based on an appropriate assessment of quality, not quantity, of research, balanced against bedside skills. And a $\mathrm{PhD}$ or $\mathrm{MD} / \mathrm{PhD}$ programme for clinicians should be introduced. Despite public censure, the Bavarian Chamber of Physicians allows Herrmann to continue practising as a clinician in Munich. So why are there no positive moves to change? Because the medical profession is deeply conservative, protective and arrogant. 